\title{
Oficinas socioculturais com crianças e jovens sob a perspectiva da Terapia Ocupacional Social
}

\author{
Giovanna Bardia, Gustavo Artur Monzelia , Maria Daniela Corrêa de Macedo ${ }^{a}$, \\ Amabile Teresa de Lima Neves ${ }^{a}$, Jéssica Santos Rocha Lopes ${ }^{b}$

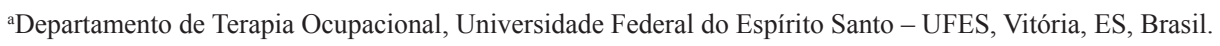 \\ bUniversidade Federal do Espírito Santo - UFES, Vitória, ES, Brasil.
}

\begin{abstract}
Resumo: Introdução: Os terapeutas ocupacionais, ao longo de sua história, defrontaram-se com a necessidade de ofertar ações concernentes às problemáticas socioculturais dos mais diversos públicos com os quais interagem, necessitando desenvolver ações pertinentes a esses contextos. Além disso, intervenções pertencentes ao âmbito da cultura, de forma focalizada, também têm sido compreendidas como da alçada deste profissional. Objetivo: Relatar a experiência do programa METUIA da Universidade Federal do Espírito Santo, que ilustra, sob o viés da terapia ocupacional social, as oficinas culturais e os acompanhamentos individuais e territoriais empreendidos durante um período de seis meses, no contexto sociocultural de uma comunidade periférica do município de Vitória, ES. Método: A construção conjunta das atividades visava à ampliação das redes sociais de suporte, à potencialização da infância e da juventude participantes e a participação social, além da construção de projetos de vida próprios às suas identidades culturais. Resultados: As oficinas culturais proporcionaram a identificação de diferentes demandas colocadas pelas crianças, pelos adolescentes e jovens, partindo da articulação entre distintos olhares e reflexões que se colocavam em choque por meio do reconhecimento da alteridade entre os grupos e os terapeutas ocupacionais. Conclusão: Almeja-se que experiências aqui retratadas possam contribuir para a consolidação das ações dos terapeutas ocupacionais no âmbito da cultura, trazendo elementos que possam promover reflexões para um campo que ainda necessita ser sistematizado como detentor de práticas e pesquisas nesta categoria profissional, sobretudo no campo social.
\end{abstract}

Palavras-chave: Cultura, Criança, Jovem, Terapia Ocupacional Social.

\section{Socio-cultural workshops with children and youth from the Social Occupational Therapy perspective}

\begin{abstract}
Introduction: Occupational therapists, throughout the history, faced the need to offer actions pertaining to socio-cultural issues in different populations with whom they interact, being required to develop actions relevant to these contexts. In addition, interventions specifically within the scope of culture have also been understood as the scope of this work. Objective: To report the METUIA experience of the 'Universidade Federal do Espirito Santo', illustrating, from the perspective of social occupational therapy, cultural workshops and individual and territorial follow-ups during six months, in the cultural context of a suburb neighborhood in the city of Vitoria, ES, Brazil. Method: The activities collective development aimed at expanding the support of social networks, the empowerment of children and youth participants and the joint construction of processes of autonomy, social participation and life projects to their own cultural identities. Results: The cultural workshops provided the identification of different demands by the children, adolescents and young people, based on the articulation between different views and reflections that were placed in shock through the recognition of alterity between the groups and occupational
\end{abstract}

Autor para correspondência: Giovanna Bardi, Departamento de Terapia Ocupacional, Universidade Federal do Espírito Santo, Avenida Marechal Campos, 1468, Maruípe, CEP 29040-090, Vitória, ES, Brasil, e-mail: bardi.giovanna@gmail.com

Recebido em Abr. 28, 2015; $1^{\text {a }}$ Revisão em Nov. 28, 2015; Aceito em Fev. 11, 2016. 
therapists. Conclusion: It is hoped that the experiments described here can contribute to the consolidation of occupational therapists actions in culture, bringing elements that can promote reflections for a field that still needs to be systematized as a producer of professional practice and research, especially in the social area.

Keywords: Culture, Child, Youth, Social Occupational Therapy.

\section{Introdução}

Os terapeutas ocupacionais, no decorrer histórico de sua atuação profissional, defrontaram-se com a necessidade de ofertar açóes culturalmente concernentes aos mais diversos públicos com os quais interagem. Colocou-se, portanto, para esses profissionais, a tarefa de desenvolver atividades culturalmente pertinentes, deslocando o próprio técnico de sua centralidade e provocando sua imersão nas práticas culturais e territoriais, muitas vezes totalmente distantes das experiências vivenciadas até então (BARROS; ALMEIDA; VECCHIA, 2007).

Dessa forma, quando o terapeuta ocupacional passou a trabalhar junto aos cotidianos dos sujeitos focos de sua intervenção, passou a haver uma implicação cultural na própria definição de terapia ocupacional, uma vez que o cotidiano, se pensado pela ótica da subjetividade, da coletividade e do contexto histórico-social, caminha para além do "treinamento das atividades de vida diária" e possui necessariamente um componente cultural do qual não pode se separar (GALHEIGO, 2003). A autora assim explica:

$\mathrm{Na}$ medida em que os estudos sobre o cotidiano incorporam a subjetividade, a cultura, a história e o poder social como elementos que influem na compreensão do fenômeno, eles definitivamente rompem com qualquer leitura de caráter mais positivista. Afirmam, desta forma, que valores mudam de acordo com as diferentes culturas, mudam ao longo da história e podem ser diferentes mesmo dentro de uma mesma sociedade em determinado momento (GALHEIGO, 2003, p. 107, grifo nosso).

Além da proposição de açôes concernentes aos contextos culturais dos sujeitos ${ }^{1}$, os terapeutas ocupacionais também se utilizam, desde os primórdios do seu desenvolvimento profissional, das atividades artísticas e culturais ${ }^{2}$ enquanto uma metodologia de trabalho ou um recurso para articular as mais diversas demandas, de ordem física, mental ou social, referentes aos indivíduos que são foco de intervenção (CASTRO; SILVA, 2002; LIMA; YASUI, 2014). Neste caso, uma infinidade de propostas pode ser elaborada, como, por exemplos: produção de pintura em tela, produção de vídeos, blogs, peças teatrais, ida a espaços de produçóes artísticas e culturais (exposiçóes, orquestras, dentre outros) (SILVA; LIMA, 2014).

No que compete às açóes focalizadas diretamente na cultura, temos colocada hoje a discussão sobre a "Acessibilidade Cultural", que possui, como centralidade, a articulação das legislaçóes conquistadas no campo dos direitos humanos e da deficiência. Trazem à tona um contexto de luta, via movimentos sociais, pelos direitos das pessoas com deficiência através da perspectiva da inclusão social e da Convenção da Diversidade Cultural (DORNELES, 2014). Há o estabelecimento de que pessoas com necessidades especiais devem ter direito a acessar todo e qualquer espaço público, inclusive os espaços culturais. Para isso, devem ser realizadas diversas adaptaçóes nestes espaços, bem como capacitaçóes de recursos humanos e promoção de políticas públicas ${ }^{3}$.

Por fim, temos o campo social da terapia ocupacional enquanto um desenvolver de açóes voltadas para a cultura, quando se coloca o desafio de pensar determinados grupos e comunidades que foram - e são - historicamente subjugados: povos indígenas, quilombolas, comunidades tradicionais, indivíduos moradores de bairros periféricos, além de diversas identidades historicamente oprimidas por questóes étnicas, sexuais, de gênero, dentre outras.

O campo social fundamentou as suas bases teóricas em um contexto de extremas mudanças econômicas e políticas, no final da década de 1980, assumindo diferentes áreas de atuação, ancoradas por políticas sociais implementadas em uma conjuntura de democratização da sociedade brasileira. Em conjunto com os movimentos de Reforma Sanitária e Reforma Psiquiátrica, a terapia ocupacional passou a se direcionar pela desconstrução da lógica asilar e pela construção de um olhar focado para as açóes nos territórios das vidas dos sujeitos, organizando serviços e pensando estratégias de ação para além dos muros institucionais (BARROS; GHIRARDI; LOPES, 2002).

A proposta de um campo social na terapia ocupacional assume, nos anos 1990, sentidos novos e diversas implicaçóes, resultado de esforços em renunciar à adoção de modelos redutores e de perspectivas simplificadoras da compreensão das 
questôes sociais, redefinindo objetos e instrumentos de intervenção, estabelecendo a profissão em bases mais largas (BARROS; GHIRARDI; LOPES, 2002).

Com o objetivo de fortalecer as redes de suporte social (formal e informal) desses grupos culturais e trabalhar os processos de vulnerabilidade social a que se encontram suscetíveis, têm-se promovido diversas ações que buscam promover acesso, autonomia e auxiliar no processo de direito à existência desses grupos em suas diversidades culturais (COSTA, 2012).

Compreende-se a necessidade de se produzirem, em conjunto, açôes voltadas aos grupos culturais, não apenas no nível da terapia ocupacional, por diversas perspectivas, a depender das demandas próprias de cada grupo em seus diferentes territórios e distintos contextos. Para a terapia ocupacional social, esses contextos aparecem, principalmente, interligados às problemáticas que se relacionam a um histórico de não reconhecimento legal dos diretos desses grupos e/ou de um processo de estereotipação e subjugação de alguns de seus conceitos e práticas.

Nesta perspectiva, se produzem açóes, no contexto da terapia ocupacional, não porque determinados grupos culturais são portadores de "problemas" ou "questôes culturais", mas pelo fato de se identificarem situações históricas e contextuais de violências, negligências e/ou outras formas agressivas de se lidar com as diferenças no contexto dos distintos territórios sociais e de significação.

Com relação ao campo dos direitos culturais, Gohn (2008) nos esclarece que se trata de:

[...] temas, questôes e problemáticas relacionadas às múltiplas dimensões do ser humano tais como gênero, raça, etnia, religião, faixas etárias, nacionalidades. Abrange também o produto e a obra produzida por esses seres humanos em suas relaçôes sociais [...]; expressões artísticas, manifestaçôes culturais e folclóricas locais, regionais e nacionais; práticas de ensino e aprendizagem; esporte e lazer. O campo dos direitos culturais penetra também no modo e estilo de vida cotidiana [...] (GONH, 2008 apud FERNANDES, 2010, p. 38).

Nesse sentido, segundo Geertz (1989), a cultura seria como uma teia de significados que grupos humanos estabelecem sobre as relaçôes entre si e com a natureza, sobre os modos de vida, sobre costumes, crenças e identidades. A cultura pode ser conceituada também como a capacidade singular da espécie humana de ordenar e desordenar o mundo em termos simbólicos, bem como nomear e distinguir a organização da "experiência humana" e da "ação humana" por meio de seus valores e significados (SAHLINS, 1997).

Assim, as oficinas culturais, para a terapia ocupacional, se configuram como momentos de compartilhamento de açôes pertinentes aos contextos dos indivíduos e grupos. Estes encontros, mediados por diversos fazeres e experiências, colocam em pauta as diferentes produçóes de significado, baseadas nos processos de alteridade dos sujeitos envolvidos nas oficinas. Os objetivos principais das oficinas culturais estão no compartilhamento das diferentes formas de produção e significação dos fazeres individuais e coletivos; no reconhecimento de saberes e práticas subjugados no contexto social mais amplo, e na produção de um espaço democrático, capaz de reconhecer e valorizar diferentes práticas locais e suas significações.

O núcleo UFES do projeto METUIA ${ }^{4}$, criado no ano de 2014, pela articulação de três principais projetos de Extensão ${ }^{5}$ coordenados pelos docentes da área social do curso de terapia ocupacional, tem continuamente se dedicado à produção de conhecimento e formação profissional em terapia ocupacional social, no Estado do Espírito Santo. Há uma defesa pela necessidade de uma abordagem cultural complexa, propondo-se tanto a realizaçáo de atividades culturais como recurso para a articulação das demandas sociais colocadas quanto a produção de açóes que visam diretamente à inserção e ao pertencimento cultural de grupos vulnerabilizados (LOPES et al., 2008).

No que compete à produção de açóes culturais, traremos, neste manuscrito, a experiência territorial produzida durante um período de seis meses em um dos projetos de extensão do núcleo METUIA - UFES. As situações aqui retratadas almejam contribuir na consolidação das açóes dos terapeutas ocupacionais no contexto sociocultural ${ }^{6}$, trazendo elementos que possam promover reflexóes para um campo que ainda necessita ser afirmado enquanto detentor de práticas e pesquisas em terapia ocupacional.

\section{Oficinas com Crianças e}

$$
\begin{aligned}
& \text { Jovens do Bairro de Santos } \\
& \text { Reis, Vitória, ES }
\end{aligned}
$$

Trata-se de um relato de experiência do Programa METUIA da Universidade Federal do Espírito Santo (UFES), vinculado ao projeto de extensão “Terapia Ocupacional Social, juventudes e intervenções urbanas e culturais", localizado em Vitória, no bairro Santos Reis, pertencente ao território São Pedro da Regiấo VII. 
Administrativamente, o município de Vitória, configurado como o quarto que mais mata jovens, principalmente pobres e negros, em todo o território nacional', divide-se em sete Regiốes: Região I - Centro; Região II - Santo Antônio; Região III - Bento Ferreira; Região IV - Maruípe; Região V - Praia do Canto; Região VI - Continente e Região VII - São Pedro (BASTOS et al., 2009).

O território onde empreendemos o projeto de extensão corresponde ao Bairro Santos Reis, pertencente à Região de São Pedro, mais conhecida como "Grande São Pedro", localizada na porção oeste da Ilha de Vitória. A ocupação desta região se deu na década de 1970, com a invasão das terras e do manguezal, e a construção desordenada de moradias em meio ao lixo, que era sistematicamente depositado pelo governo municipal. Na década seguinte, foi dado início à sua urbanização, que acontecera de forma extremamente desordenada (MATTOS, 2008).

No ano de 1983, a situaçáo de calamidade da região deu origem a um documentário televisivo intitulado de "Lugar de Toda Pobreza" que retratou o "Lixão de Sáo Pedro", como era chamado o local de despejo do lixo da cidade. Este foi, gradativamente, tornando-se uma fonte de sobrevivência de centenas de pessoas com a coleta e a venda de papéis, plásticos e vidros, e o reaproveitamento de alimento (SIQUEIRA, 2001).

Apesar da intensificação dos investimentos em urbanização, recuperação e preservação ambiental na região, a partir da década de 1990, São Pedro permanece como espaço altamente excludente, apresentando alto índice de pobreza e violência (MATTOS, 2008). Dados referentes ao início dos anos 2000 nos trazem São Pedro como a região mais violenta do município, responsável por 19\% dos óbitos por violência; destes, 92,5\% foram notificados como homicídios (BASTOS et al., 2009).

Tendo em vista esses dados, o projeto se estruturou como uma forma de potencializar a juventude da localidade no sentido da apropriaçáo do espaço comunitário, construindo em conjunto formas de autonomia e participação social, e fortalecendo seus desejos e projetos de vida, de acordo com a cultura local. Realizamos açôes e atividades intersetoriais no que tange à saúde, à educação, à assistência social, ao esporte, à cultura e ao lazer, promovendo reflexôes sobre as diferenças e problemáticas sociais no cotidiano próprio da juventude deste local.

Logo nas primeiras idas ao território, as crianças começaram a aparecer nos espaços que, inicialmente, ofertávamos especificamente para os jovens do bairro. Diante disso, o grupo se estruturou para propor atividades também condizentes ao público infantil da localidade. A partir disso, as crianças, em sua maioria de 6 a 12 anos, passaram a frequentar assiduamente as nossas oficinas.

O projeto foi criado no ano de 2014 através de parcerias com as redes de suporte da própria comunidade de Santos Reis e com outros programas de ação social. A comunidade católica, importante parceira, nos cedeu um espaço para a realização das oficinas; nesse espaço, funcionava, outrora, algo como um projeto de reforço escolar, chamado na comunidade de "Escolinha". O padre, representante da comunidade da Região de São Pedro e possuidor de vasto conhecimento do território, atuou como facilitador para nossa entrada no bairro, nos apresentando para os principais líderes locais e nos auxiliando na divulgaçáo das nossas oficinas.

Destacamos que a relação de proximidade existente entre o líder religioso e a liderança do tráfico de drogas da localidade fora imprescindível para a constituiçâao do nosso projeto. Logo no início das negociaçóes com o padre, ele nos informou que o representante do tráfico havia, mais de uma vez, pedido a ele que algo fosse desenvolvido para os jovens do bairro no antigo espaço da "Escolinha". Ele, então, havia buscado parceiras no município que pudessem empreender algo para essa população. Ficara sabendo do METUIA - UFES através de uma aluna do curso de Terapia Ocupacional, frequentadora de suas missas.

Para a liderança do tráfico de drogas, fazia-se necessário disponibilizar aos jovens do bairro serviços públicos ou de interesse privado, como açóes de lazer, educação, saúde, dentre outras, uma vez que estas eram quase inexistentes. Isso fez com que nossa inserçáo na Região de São Pedro fosse percebida como de interesse da populaçáo, apesar de não compreenderem logo de início nossos objetivos com as oficinas culturais. Com o passar do tempo, tiveram a compreensão de que estávamos lá para atender diferentes demandas dos moradores da região.

A outra parceria se deu com o Projeto Raízes ${ }^{8}$, desenvolvedor de açóes voltadas para a juventude pobre, sobretudo negra, do município de Vitória. Juntos, adentramos o espaço que nos fora cedido e passamos a organizar diversas atividades para o público juvenil. Durante dois dias da semana (terça e quinta), pelo período da manhá, realizávamos o grupo da terapia ocupacional, nomeado pelos próprios jovens de "Oficinas de Fazer Junto", no qual jovens, como também crianças, propunham o que seria feito dentro do espaço. Nos outros dias, o Projeto Raízes coordenava oficinas de informática, dança e fotografia. 
As oficinas de atividade realizadas tiveram como base os pressupostos da terapia ocupacional social (BARROS; GHIRARDI; LOPES, 2002) e em Paulo Freire (1979), sendo compreendidas como recurso mediador da aproximaçáo, do acompanhamento e da apreensão das demandas, visando ao fortalecimento dos sujeitos individuais e coletivos (LOPES et al., 2011), além de promover a valorização cultural, afirmaçóes identitárias, exercícios de cidadania e emancipação social (BARROS; ALMEIDA; VECCHIA, 2007).

Vale destacar que, às segundas feiras, no período matutino, eram feitas supervisôes do projeto na Universidade para discussão das intervençôes realizadas e planejamentos das próximas açôes. Também é relevante apontar que o Programa de Extensão METUIA - UFES contou com o apoio da Pró-Reitoria de extensão da UFES, que permitiu ao projeto ter um bolsista, extensionista, e também ser composto por estagiários. Além disso, o Departamento de Terapia Ocupacional nos cedeu uma técnica terapeuta ocupacional para atuar junto a este e outros projetos da área social.

A seguir, traremos um relato das principais oficinas de atividades realizadas com as crianças e os jovens de Santos Reis, Vitória, ES, elucidando os fatos mais marcantes e os principais desdobramentos das açốes empreendidas, principalmente no que concerne aos acompanhamentos individuais que puderam ser traçados a partir do espaço coletivo.

\section{Entre Subir o Morro, a Apreensão da Realidade Sociocultural e a Produção de Significados Coletivos}

A Região de São Pedro e, mais especificamente o bairro de Santos Reis, é um grande complexo, com áreas de antigo manguezal cercadas por grandes morros, ruas estreitas e vielas que se ligam, de forma não projetada. A maior parte dos habitantes de Santos Reis está localizada na área dos morros, com uma infinidade de tipos de construçáo, desde casas de alvenaria a barracos de madeira, construídos em um tipo desordenado de apropriação do espaço para a construção civil.

Em função das características urbanas e geográficas, nossas intervenções sempre começavam antes mesmo de se chegar ao espaço, no topo de um dos morros. O processo de subida do morro era realizado por três estagiários e uma aluna extensionista do Programa METUIA, uma técnica terapeuta ocupacional e um professor responsável pelo campo. Nos primeiros dias do projeto, essa ação era vista pelos próprios moradores do bairro de diversas formas. Para alguns, fazíamos parte de um grupo que vinha "ajudar a juventude local”; para outros, poderíamos ser considerados "invasores" da vida própria do bairro, ou ainda "clientes do tráfico de drogas", bastante desenvolvido na região.

Com o passar dos dias, os moradores foram se acostumando com nossa presença e, aos poucos, ganhávamos cumprimentos e companhias para a subida pelas longas escadarias. Nesses momentos, acabávamos por conhecer onde se localizavam as casas dos participantes das oficinas, quem eram os familiares, ficávamos sabendo também as notícias recentes e os principais acontecimentos do bairro. As conversas e visitas traziam diversos elementos com grande potencial para nossas intervençôes e para a discussão das realidades vivenciadas pelos moradores daquele bairro.

No espaço das oficinas, a atividade de culinária foi a primeira sugestão das crianças. O espaço ainda não chamava a atençấo dos jovens e dos demais membros da comunidade; sabendo disso, o nosso objetivo era que as atividades de culinária funcionassem como um convite, uma forma de divulgação, pois as crianças que participavam levavam para dentro de suas casas o que tinham feito no espaço comunitário e, dessa forma, o número de participantes foi aumentando.

Já neste ponto, era possível o compartilhamento de símbolos culturais, uma vez que acabávamos por conhecer cada vez mais o cotidiano dos participantes e do lugar onde estávamos, através da interação entre eles e deles conosco, conversando e discutindo sobre os costumes alimentares. Em relaçôes dialógicas e de alteridade, eram-nos contadas as diferentes configurações familiares, as diversas atividades relacionadas ao trabalho, os locais de moradia, as relaçóes entre os participantes e até mesmo o contexto do próprio bairro.

Concomitante à oficina de culinária, realizávamos uma atividade de leitura compartilhada. Em nosso local de oficinas, existiam diversos livros, principalmente por já ter sido um local de reforço e alfabetização para ensino. A atividade de leitura compartilhada era feita em grupo e de diversas maneiras: em alguns momentos, cada participante lia um trecho específico de um livro; em outros, acontecia de um participante ler o livro todo individualmente e contar para o coletivo suas impressóes, tudo a depender do modo como cada participante se colocava no coletivo.

O objetivo era gerar discussão sobre o que era lido entre eles, o que sempre trazia assuntos de 
suas próprias realidades vividas e da memória social compartilhada na comunidade de Santos Reis. A maioria dos adolescentes e crianças que participava tinha os responsáveis analfabetos ou tinha os estudos interrompidos por motivo de gravidez, emprego, inserção no tráfico de drogas, dentre outros tantos motivos que acabavam por "competir" com a trajetória escolar.

Outro exemplo de atividade realizada, a oficina de jardinagem, também surgiu das atividades de leitura compartilhada. Através de um livro de literatura simples sobre sementes, um dos jovens que frequentavam o espaço demonstrou interesse e disponibilidade para a realização da oficina. O objetivo principal era de que os jovens e as crianças daquele bairro pudessem se apropriar do espaço que já era da comunidade, ressignificando inclusive as práticas que aconteciam ali e percebendo que uma atividade de jardinagem poderia ser um meio de promover formas de cuidado coletivo e corresponsabilizaçáo com o próprio local.

Em outra atividade, num processo de confecção de bolas com retalhos de tecido, para jogos esportivos, o objetivo principal era estimular o lazer, a diversão e a apropriação dos espaços comunitários para estas atividades. Com esta atividade, percebemos a necessidade de nos organizarmos para investir na produção de espaços de lazer no bairro, acionando representantes da comunidade para a cobrança organizada das entidades governamentais sobre as condiçôes de lazer em Santos Reis. Juntamente com os jovens, foram feitas reunióes de articulação com os moradores e todos os envolvidos no projeto, para a estruturação de pautas sobre o lazer na comunidade.

Trabalhamos também com a confecção de fantoches para a realização de peças teatrais, proporcionando rodas de criação de histórias, nas quais as crianças e jovens escreviam com liberdade os conflitos de seus cotidianos em cada história. Os terapeutas ocupacionais mediavam as situações, provocando reflexôes coletivas aos temas trazidos nas histórias apresentadas. Em vários momentos de criação, discutíamos sobre sexualidade, violências, questóes familiares, preconceitos, autoimagem, respeito às diferenças, e questôes culturais.

Nestes momentos, discutíamos também a função do terapeuta ocupacional, na área social, atuando no território e discutindo sobre formas de combate a opressôes, promovendo, nestes momentos, reflexôes sobre o cotidiano e o contexto sociocultural da comunidade, e criando estratégias para a diminuição das desigualdades sociais, promovendo em conjunto formas de cidadania e participação social.
Os preparativos de datas comemorativas também eram feitos nos dias de oficina de atividades da terapia ocupacional, como, por exemplo, nas vésperas do Natal, quando pudemos discutir temas relacionados à própria concepção desta época para eles. Decidimos juntos confeccionar cartóes de Natal para que pudéssemos presentear familiares ou amigos. Aos poucos, fomos identificando que todas as referências de "Natal" que eles tinham eram referências exteriores à própria realidade e ao próprio país. Os primeiros cartóes eram recheados de "bonecos de neve", "frio" e de "árvores (pinheiros) de Natal". Começamos então a questionar se alguém já tinha visto neve, ou se na cidade deles fazia frio na época de Natal, ou se alguma vez já tinham visto um pinheiro.

Neste momento, todos os participantes começaram a perceber que esta ideia de Natal que eles estavam propondo era uma reproduçáo de um Natal que não era deles. Todos começaram a dizer que, na verdade, no Natal, eles vão à praia, náo tem neve e, pelo contrário, tem muito sol. E, a partir daí, começaram a recolocar seus próprios conceitos desta festa e náo apenas reproduzir essa ideia já colocada. Por fim, fizeram "Pitangueiras", "Mangueiras" e "Abacateiros" de Natal.

A fim de que o espaço pudesse adquirir uma nova identidade, discutimos muitas vezes com os jovens sobre a possibilidade de mudar a fachada do lado externo do local comunitário, coberta de pinturas que lembravam a antiga "Escolinha”. Organizamos, entáo, uma reuniáo junto à comunidade para pensarmos sobre a necessidade de transformar e quais redes próximas poderíamos acionar para efetuar o projeto. A discussão gerou mobilização de alguns jovens do território para buscar parceiros que pudessem auxiliar na pintura da parte externa, que foi realizada coletivamente em um dos últimos dias de oficina.

Compreendendo a importância de que os jovens se apropriassem também de outros espaços na região da cidade de Vitória e sabendo das possibilidades de compartilhamento nas vivências fora do contexto exclusivo do próprio bairro, por iniciativa de um dos jovens, organizamos um passeio numa região nobre e bastante importante da cidade. Entendemos que a (de)limitaçấo geográfica para estes jovens está bastante colocada, uma vez que eles não sáo proibidos de sair do próprio bairro, mas todas as vezes que tentam se deslocar passam constantemente por processos de "complicação" colocados por diferentes fatores, como a própria formaçấo geográfica da cidade, o transporte público ou mesmo a abordagem policial nestes locais. 


\subsection{Desdobramentos do processo de realização das oficinas: $o$ acompanhamento individual e territorial em contexto sociocultural}

Começamos os acompanhamentos singulares com Alice ${ }^{9}$, que, durante as oficinas, demandava bastante atenção pelo seu jeito introspectivo com os demais jovens do projeto. Alice tinha 15 anos, era estudante, possuía dois irmãos mais novos e morava com os pais em Santos Reis. A aproximação com ela foi estabelecida principalmente na oficina de "Leitura Compartilhada", na qual, apesar de demonstrar muito interesse, tinha dificuldades na leitura e na interação com os demais participantes de sua idade. Em momentos de maior privacidade, ela trazia questóes relacionadas à situação financeira de sua família e ao autoritarismo do pai.

Com o processo de vinculaçáo mais fortalecido, passamos a acompanhar também a família de Alice, que trazia outras situaçóes complexas, dentre as quais, o fato de que sua mãe apresentava um diagnóstico de transtorno mental, seu pai estava desempregado e havia uma dificuldade financeira séria que, por vezes, os fazia depender dos vizinhos mais próximos para ter acesso às refeiçôes diárias. Diante das variadas demandas, aos poucos começamos a acionar as redes sociais locais, como a Unidade Básica de Saúde (UBS) do bairro, pelo contato realizado com o agente comunitário do Programa de Saúde da Família (PSF), e aconselhamos que a família solicitasse o credenciamento no Centro de Referencia de Assistência Social (CRAS).

Acompanhávamos Alice em muitas de suas atividades, estimulando a interação com outros jovens e o seu protagonismo durante as oficinas. No final do ano letivo, ela nos solicitou que fossemos à escola na qual estudava, para ajudar em sua transferência para outra escola mais próxima de sua casa. $\mathrm{O}$ contato com a escola permitiu uma análise, sob o olhar da direção escolar, dos avanços que Alice teve no período em que frequentava as oficinas do projeto METUIA.

Alice participava de uma turma de "correçấo de fluxo" de alunos com dificuldade de aprendizagem e atraso letivo, mas demonstrou, segundo relatos de sua professora, melhoras em seus processos de comunicação, sendo mais ativa durante as aulas e crítica em diversos assuntos, questionando e opinando sobre sua situação no contexto escolar.

A partir das conversas tanto com professores e diretores da escola quanto com os pais de Alice, e entendendo nâo ser o desejo dela a mudança para outra escola, o que possivelmente atrapalharia seu desempenho escolar, propusemos uma mediação entre escola e família com o objetivo de esclarecer possíveis questóes e solucionar a situação de Alice, para que ela inclusive tivesse a possibilidade de fala nessa tomada de decisão.

Outro acompanhamento foi feito com um jovem também de 15 anos, Beto. O horário de estudos de Beto coincidia com o horário em que aconteciam as oficinas do projeto do METUIA. Por isso, quando ele aparecia no espaço para participar das oficinas, sabíamos que não tinha ido à escola, por algum motivo, e esse fato sempre acabava por nos fazer aproximar para uma conversa.

Beto morava com a mãe, sua tia e dois irmãos mais novos, tinha muitos amigos na comunidade e era muito próximo também dos outros jovens que trabalhavam no tráfico de drogas local. Ele tinha muito interesse nas oficinas e era bastante participativo na tomada de decisóes para a transformação do espaço, possuía grande interesse nos temas relacionados a desenhos e grafites. Por conta de sua impossibilidade de frequentar as oficinas toda semana, buscamos nos comunicar com ele por redes sociais e, desta relaçáo via internet, Beto teve a iniciativa de criar um grupo em uma rede social para o compartilhamento de informaçôes com outros jovens que também não podiam estar no espaço do projeto. O espaço, além disso, funcionava para exibir os trabalhos relacionados ao desenho e grafite, além de compartilhar alguns eventos locais.

Convidamos outros jovens que trabalhavam com a arte que ele tanto admirava para participar do grupo, incentivando outros jovens, de outros locais, a divulgar seus trabalhos nesta mesma plataforma.

\section{Conclusão}

As experiências apresentadas nos revelam, primeiramente, o reconhecimento territorial realizado por um grupo de terapeutas ocupacionais com o intuito de compreender como se configurava o bairro, quem eram as principais lideranças da regiáo, como se organizavam internamente para o acesso aos direitos sociais, quais eram as principais demandas socioculturais colocadas pela população, dentre outros aspectos. Essa tarefa, contudo, apesar de inicial, esteve presente em todos os momentos de intervençáo na localidade, uma vez que todos estes aspectos estáo em constante movimento e necessitam de tempo e constituição de vínculo, para serem acessados. 
A estruturação das diversas atividades realizadas se deu a partir das crianças e dos jovens que participavam das nossas oficinas, numa permanente negociação com os terapeutas ocupacionais, respeitando sempre os limites institucionais, as diversidades culturais, os desejos/vontades e as necessidades.

As oficinas culturais proporcionaram a possibilidade de identificação de diferentes demandas colocadas pelas crianças, pelos adolescentes e jovens, partindo da articulação entre distintos olhares e reflexôes que se colocavam em choque por meio do reconhecimento da alteridade entre os grupos e os terapeutas ocupacionais. Além disso, as oficinas culturais se configuraram também como um recurso mediador destas alteridades, propondo um ambiente capaz de produzir a reflexão sobre as percepçóes individuais e coletivas, tanto dos terapeutas ocupacionais quanto dos outros participantes das oficinas culturais.

As reunióes em prol da organização de açóes políticas para o acesso dos moradores do bairro ao lazer, bem como a "repaginação" da fachada do espaço onde ocorriam as oficinas, vislumbraram promover o pertencimento de jovens, crianças e adultos ao bairro, o exercício da autonomia e, mais uma vez, o acesso aos seus direitos sociais e culturais.

As diversas ações dos terapeutas ocupacionais, neste contexto, se deram a partir do embasamento teórico-metodológico da terapia ocupacional social e da percepçáo de que as questôes de diversidade cultural são intrínsecas a um modo específico de se compreenderem e se produzirem determinadas intervençôes coletivas.

Desta forma, ao propor açóes e intervençóes no contexto da terapia ocupacional, mais especificamente na área social e na cultura, se faz necessário compreender quais são os esquemas conceituais e teóricos que podem nos auxiliar a compreender determinada realidade empírica, bem como produzir recursos metodológicos culturalmente pertinentes para nossas açóes.

\section{Referências}

BARROS, D. D.; ALMEIDA, M. C.; VECCHIA, T. C. Terapia Ocupacional social: diversidade, cultura e saber técnico. Revista de Terapia Ocupacional da Universidade de São Paulo, São Paulo, v. 18, n. 3, p. 128-134, 2007.

BARROS, D. D.; GHIRARDI, M. I. G.; LOPES, R. E. Terapia Ocupacional social. Revista de Terapia Ocupacional da Universidade de São Paulo, São Paulo, v. 13, n. 2, p. 95-103, 2002.
BARROS, D. D.; LOPES, R. E.; GALHEIGO, S. M. Terapia Ocupacional social: concepçóes e perspectivas. In: CAVALCANTI, A.; GALVÃO, C. (Org.). Terapia Ocupacional: fundamentação e prática. Rio de Janeiro: Guanabara Koogan, 2007. p. 347-353.

BASTOS, M. J. R. P. et al. Análise ecológica dos acidentes e da violência letal em Vitória, ES. Revista de Saúde Pública, São Paulo, v. 43, n. 1, p. 123-132, 2009.

CASTRO, E. D.; SILVA, D. M. Habitando os campos da arte e da terapia ocupacional: percursos teóricos e reflexóes. Revista de Terapia Ocupacional de Universidade de São Paulo, São Paulo, v. 13, n. 1, p. 1-8, 2002.

COSTA, S. L. Terapia Ocupacional social: dilemas e possibilidades de atuaçáo junto a povos e comunidades tradicionais. Cadernos de Terapia Ocupacional da UFSCar, São Carlos, v. 20, n. 1, p. 43-54, 2012.

DORNELES, P. S. Acessibilidade cultural: uma nova atuação dos terapeutas ocupacionais. In: SANTOS, V.; GALLASSI, A. D. (Org.). Questöes contemporâneas da Terapia Ocupacional na América do Sul. Curitiba: CRV, 2014. p. 151-158.

FERNANDES, N. M. A cultura como direito: reflexóes acerca da cidadania cultural. Latitude, Maceió, v. 4, n. 1, p. 33-53, 2010.

FREIRE, P. Educação como prática da liberdade. Rio de Janeiro: Paz e Terra, 1979.

GALHEIGO, S. M. O cotidiano na terapia ocupacional e contexto histórico-social: cultura, subjetividade. Revista de Terapia Ocupacional da Universidade de São Paulo, São Paulo, v. 14, n. 3, p. 104-109, 2003.

GEERTZ, C. A interpretação das culturas. Rio de Janeiro: Zahar, 1989.

GOHN, M. G. O protagonismo da sociedade civil: movimentos sociais, ONGs e redes solidárias. São Paulo: Cortez, 2008.

LIMA, E. M. F. A.; YASUI, S. Territórios e sentidos: espaço, cultura, subjetividade e cuidado na atenção psicossocial. Saúde em Debate, Rio de Janeiro, v. 38, n. 102, p. 593-605, 2014.

LOPES, R. E. et al. Juventude pobre, violência e cidadania. Saúde e Sociedade, São Paulo, v. 17, n. 3, p. 63-76, 2008.

LOPES, R. E. et al. Oficinas de atividades com jovens da escola pública: tecnologias sociais entre educação e terapia ocupacional. Interface: Saúde, Educação, Comunicação, Botucatu, v. 15, n. 36, p. 277-288, 2011.

MATTOS, R. F. S. Desigualdade sócio-espacial e violência urbana: a Região Metropolitana da Grande Vitória. 2008. 182 f. Tese (Doutorado em Ciências Sociais) 
- Pontifícia Universidade Católica de São Paulo, São Paulo, 2008.

SAHLINS, M. O. "Pessimismo sentimental" e a experiência etnográfica: por que a cultura não é um “objeto" em via de extinção (parte I e II). Mana, Rio de Janeiro, v. 3, n. 2, p. 103-150, 1997.
SILVA, J. A.; LIMA, E. M. F. A. Ocupar-se de nada, povoar-se de muito: experimentaçóes entre as artes e a vida. Cadernos de Subjetividade, São Paulo, v. 16, p. 151-162, 2014.

SIQUEIRA, M. P. S. Industrialização e empobrecimento urbano: o caso da Grande Vitória 1950-1980. Vitória: EDUFES, 2001.

\section{Contribuição dos Autores}

Giovanna Bardi e Gustavo Artur Monzeli colaboraram com o planejamento e coordenação das açôes, redação e revisão do texto. Maria Daniela Corrêa de Macedo e Amabile Teresa Lima Neves colaboraram com o planejamento das açóes e revisão do texto. Jéssica Santos Rocha Lopes colaborou com a redação do texto. Todos os autores aprovaram a versão final do texto.

\section{Notas}

${ }^{1}$ Sobre este aspecto, faz-se importante ressaltar que há ainda uma lógica centrada, de determinada forma, na demanda clínica dos sujeitos de intervenção que, por vezes, ignora diversos aspectos de sua subjetividade e coletividade, inclusive seu contexto cultural.

${ }^{2}$ Ressalta-se que, neste contexto, os autores citados compreendem como atividades artísticas e culturais aquelas que se relacionam às distintas manifestaçôes e produçóes caracterizadas pelas artes plásticas, cênicas, musicais, dentre outras, compreendendo o artístico e o cultural como produto localizado e contextualizado, e que, portanto, pode ser disponibilizado, acessado.

${ }^{3}$ Nessa intervenção (mas não somente), torna-se bastante pertinente o trabalho do terapeuta ocupacional enquanto promotor e/ou gestor de políticas públicas voltadas para a cultura. Há uma coerência na ação do terapeuta ocupacional por essa perspectiva, uma vez que este profissional pensa no acesso dos sujeitos de intervençáo nos mais variados âmbitos da vida e do cotidiano.

${ }^{4}$ O Projeto METUIA se constituiu, em 1998, em três universidades paulistas (USP, UFSCar e PUC-São Paulo), como um grupo interinstitucional com açóes no âmbito do ensino, da pesquisa e da extensão em defesa da cidadania das populações em processos de ruptura das redes sociais de suporte. Atualmente, quatro núcleos estão em atividade: o da Universidade de São Paulo (USP) e o da Universidade Federal de São Carlos (UFSCar), o da Universidade Federal de São Paulo (UNIFESP) e, mais recentemente, o da Universidade Federal do Espírito Santo (UFES) (BARROS; LOPES; GALHEIGO, 2007).

${ }^{5}$ Compóem o Programa de Extensão METUIA - UFES, os seguintes projetos: “Terapia Ocupacional e os jovens Guarani do Espírito Santo: diálogos e oficinas culturais”, "Terapia ocupacional social, juventudes e intervençôes urbanas e culturais" e "Grupo de estudos sobre a terapia ocupacional social: produção de conhecimento e formação profissional".

${ }^{6}$ Compreendemos o contexto sociocultural como o conjunto de circunstâncias nas quais grupos culturalmente diferenciados se desenvolvem, associados a fatores políticos, econômicos, sociais, filosóficos, psicológicos, religiosos, científicos e, principalmente, culturais, ou seja, referentes aos modos de vida, às formas de organizaçáo social, à qualidade de vida e ao acesso à direitos que conduzem seus cotidianos.

7 De acordo com a Secretaria de Direitos Humanos da Presidência da República, dos dez municípios que mais matam jovens no Brasil, três são do Estado do Espírito Santo.

${ }^{8}$ O projeto Raízes faz parte do Núcleo Afro Odomodê que, desde 2006, desenvolve atividades culturais voltadas para jovens afrodescendentes residentes na cidade de Vitória. É um espaço de formação, convivência e participação que busca estimular, sensibilizar e mobilizar os jovens para a luta contra os preconceitos, violências e exclusôes.

${ }^{9}$ Todos os nomes utilizados aqui são fictícios para a preservação das identidades dos participantes. 